\section{A formação nas páginas do jornal}

\section{RESUMO}

Este artigo é resultado de uma pesquisa que procurou apontar a contribuição do periódico na construção de conceitos e práticas relativos à formação profissional. Essa investigação constatou que o periódico Zero Hora, de forma contínua e amparado por agentes sociais cujo capital simbólico têm reconhecimento do público leitor, exerce sua função de formador, instaurando saberes que, repetidos sistematicamente, possibilitam a construção de um perfil profissional para este início de século.

\section{ABSTRACT \\ This article is the result of a research that has tried to point out the contribution of periodics to the construction of concepts and practices relative to professional form-ations. Thus, that investigation discovered that the newspaper Zero Hora, in a continuos way and supported by social agents whose symbolic capital is recognized by its readers, plays as expected its formative role, establishing knowledges that, systematically repeated, make possible the construction of professional profiles in this beginning of century.}

\section{PALAVRAS-CHAVE (KEY WORDS) \\ - Jornal (Newspaper) \\ - Bourdieu \\ - A formação do sujeito (The subject formation)}

\section{Marina Patrício de Arruda ${ }^{1}$ \\ Doutoranda do PPG Serviço Social / PUCRS}

\section{Introdução}

Este artigo considera estudos realizados ao longo de minha dissertação de mestrado², na qual tratei a contribuição do periódico na construção de conceitos e práticas relativos à formação profissional.

Meu intuito na sistematização dessas idéias foi o de buscar uma leitura mais apurada do periódico, de modo a compreender melhor a dinâmica que se estabelece entre esse poderoso meio de comunicação de massa e a sociedade, no encaminhamento da formação de seus agentes sociais.

Ao me debruçar sobre as relações entre as criações sociais, interessou-me sobretudo compreender de que forma um jornal de grande expressão, a partir da credibilidade que detém junto a seu público leitor, pode orientar a formação para o século XXI.

A temática aqui analisada, além de permitir delinear os aspectos principais da construção cotidiana de conceitos, também permitiu conhecer as lutas pela legitimidade que são travadas nesse subcampo social, o jornal, bem como a participação dos agentes produtores do periódico na elaboração do pensamento pedagógico que visa a instaurar práticas exemplares. Nesta medida, embora trate de um estudo específico do texto do jornal Zero $\mathrm{Hora}^{3}$, realizado em Porto Alegre e no Estado do Rio Grande do Sul, acredito que este possa ser visto como um caso particular do possível e também como um caso exemplar, aquele que pode ocorrer em qualquer parte do mundo, considerando a circulação diária de jornais.

As concepções teóricas de Pierre Bourdieu, ${ }^{4}$ além de me possibilitar o desenvolvimento de um pensamento social crítico, também me alertaram para os 
perigos que o mecanismo da "dominação simbólica" representa para todas as esferas culturais e que também ameaçam a vida democrática e política da sociedade.

Outra consideração pertinente ao vetor teórico em questão diz respeito à noção de campo. Na perspectiva de Bourdieu, o real é relacional. Portanto, é preciso considerar que o objeto de pesquisa não está isolado de um conjunto de relações do qual retira o essencial de suas propriedades. Escolhi, então, o campo cultural, estruturado e preestabelecido, definido como espaço de posições, campo de forças e de lutas para, sobre ele, a partir das relações que ali se desenvolvem, produzir um novo olhar.

Essa nova visão do mundo social procura enxergar como o jornal ou periódico, com suas produções simbólicas, torna-se um instrumento de dominação em que o poder de impor e inculcar ocorre em certas condições de interação com os demais campos.

Tendo por objetivo investigar o fenômeno da formação engendrado pelo periódico, processei um levantamento das publicações da $\mathrm{ZH}$, que privilegiavam esta categoria no período de 1996 a 1998. Nesta perspectiva, cem artigos foram selecionados e cuidadosamente estudados.

Este trabalho de pesquisa envolveu - Curso de Pós-Graduação em Serviço Social da PUCRS, escolhido por mim para dar continuidade a meus estudos, considerando sua estreita relação com a sociologia, área na qual me graduei.

Considerando a época atual, marcada pela exigência de uma reorganização das várias instâncias sociais, que tem a sua dinâmica garantida pela interdependência e interligação desse sistema, é que me senti desafiada a repensar a formação, a partir de um jornal.

Repensando a formação profissional para o século XXI

Foi a partir da década de sessenta do século $X X$ que o ambiente dos negócios começou a mudar. Os mercados dos países desenvolvidos tornaram-se mais competitivos e a demanda por produtos diferenciados aumentou. A alta tecnologia invadiu os processos produtivos e, com a diminuição das barreiras no comércio internacional, as nações puderam competir entre si. A economia se globalizou e, neste contexto, passaram a assumir a liderança de mercado as empresas com capacidade de oferecer produtos muito diferenciados a preços altamente competitivos. Os novos processos de produção passaram a exigir trabalhadores mais qualificados.

É neste contexto que o processo de formação passa a ser questionado. Como preparar indivíduos para uma futura inserção no mundo do trabalho?

Sabe-se que a formação é um fato eminentemente histórico cujas modificações vão aparecendo na medida em que os modelos adotados revelam-se inadequados para satisfazer as necessidades emergentes.

Sob esta ótica cresce também, entre os pesquisadores, o interesse em estudar as orientações pedagógicas instauradas pelos periódicos como forma de aproximação mais efetiva e atual de nossa realidade.

Perseguindo essa proposta, foram analisados os temas debatidos por Zero Hora, como espaço que concentra todo um conjunto de teorias e práticas educativas de origem tanto oficial quanto privada. Observou-se, então, que a realidade estampada nas páginas do jornal orientava os profissionais a mudarem seu perfil, forçando-os a desenvolver novas habilidades e exigindo que dedicassem um número cada vez maior de horas ao autoinvestimento.

Prossigo estas considerações partindo do pressuposto de que a construção de conceitos e de práticas relativas à formação profissional do século XXI publicadas cotidianamente no periódico $\mathrm{ZH}$, bem como a ação pedagógica exercida junto a seus leitores, estão diretamente associadas 
à dinâmica estrutural do campo cultural (jornal $\mathrm{ZH}$ ) articulado, ao mesmo tempo, de forma interativa e/ou conflitiva, com a dinâmica estrutural dos demais campos que constituem o espaço social. Nesta direção tenta-se também não perder de vista o objetivo principal deste estudo, que busca analisar a influência do periódico ao orientar de maneira insistente o perfil do profissional do século XXI, observando as principais tendências relativas à formação para os próximos anos.

\section{Nas páginas do jornal}

A construção do conceito e de práticas relativas à formação que foram investigadas se realiza a partir de uma realidade registrada cotidianamente pelo jornal Zero Hora. As observações feitas pela imprensa num dado momento contêm percepções que nos ajudam a compor o real, na maioria das vezes, embaralhado. Destaca-se aqui que um conceito é produzido socialmente, o que implica dizer que a sua produção e reprodução são fato cotidiano, localizado no tempo e no espaço da vida dos homens.

Num mundo no qual a imprensa exerce papel preponderante ao popularizar e divulgar conceitos transferíveis para os diversos campos que constituem o social, a perspectiva adotada implicou compreender a construção social da formação através dos registros do periódico ZH. Nesse espaço de reprodução e também de produção do social, a palavra, o ditado, os provérbios, rituais de expressão, são programas de percepção e os enfrentamentos de visões e de previsões de luta propriamente política que encerram uma certa pretensão à autoridade simbólica, ao poder socialmente reconhecido. Em meio a essa luta cada agente produtor do jornal conta com uma parcela de poder relativo a seu capital simbólico, ou seja, ao reconhecimento que recebe do grupo (BOURDIEU, 1996).

Apurando os rituais de expressão contidos no periódico ZH é que se busca mostrar o dinamismo da construção de novas representações sociais voltadas à formação para o século XXI.

Um mercado de trabalho em reorganização

O periódico, para descrever o atual mercado de trabalho, apresentava o discurso de que o homem da fábrica, símbolo da classe operária, estava desaparecendo aos poucos e levando junto "seu capacete e bom pedaço das conquistas sociais". A idéia era a de mostrar o surgimento da nova classe do trabalhador do conhecimento da economia globalizada. Para apoiar este pensamento, ZH busca reforço em nomes de credibilidade da atualidade como Peter Drucker, o guru da administração moderna, cujo texto, selecionado para esta análise, apresenta uma nova era, aquela desencadeada pelo fenômeno do avanço tecnológico e pela globalização econômica. Este artigo vai trabalhando também a idéia de que o novo grupo dominante é o dos trabalhadores do conhecimento, ou seja,

"uma pessoa educada será, cada vez mais, alguém que aprendeu como aprender e continua aprendendo por toda a vida. A aquisição e distribuição do conhecimento formal poderá vir a ocupar o lugar que a aquisição e distribuição da propriedade e renda ocupou nos dois ou três séculos que chamamos de Era do capitalismo"6.

Estas palavras apontam o fato novo: a necessidade de formação contínua para uma sociedade que muda muito depressa. O destaque é dado ao aprendizado por toda a vida, adquirido de maneira formal, dentro dos espaços instituídos para a formação.

É o jornal como uma estrutura estruturada e, portanto, estruturante, anunciando os novos tempos e novos símbolos, criando instrumentos de 
integração social, que começa a fazer parte da realidade neste fim de século.

O periódico expõe em suas páginas afirmações que apontam a globalização como um processo irreversível, frente ao qual ainda nos encontramos fragilizados, mas vai arrolando outros fatos que também reforçam os benefícios possibilitados pela abertura de mercados:

"Será que os Tigres Asiáticos, na década de 80 , e a China continental, nesta década, teriam tido sucesso sem os dois instrumentos da globalização: o influxo de capitais e a abertura de mercados? ?".

Os países acima mencionados são apontados como modelo de parte do mundo que conseguiu obter ganhos e destaque através do fenômeno analisado, de modo a reforçar a importância do mesmo. Dito dessa maneira, parece que a globalização de mercados permitiu o enorme surto do crescimento asiático.

Assim, a questão da globalização da economia é discutida como sendo um fator decisivo e integrador. Os responsáveis pelos artigos de $\mathrm{ZH}$, para dar forma ao discurso no qual estabelecem o que pode ser pensado e feito, passam a exercer uma forma de dominação (conjuntural nãoestrutural) sobre um espaço de jogo que o jornal construiu, e no qual se acha colocado em situação de árbitro, impondo uma norma de objetividade e de neutralidade ${ }^{8}$. O que está em jogo é a luta pela imposição de uma visão de mundo:

"As relações de força mais brutais são, ao mesmo tempo, relações simbólicas e os atos de submissão, de obediência, são atos cognitivos que, como tais, põem em prática as estruturas cog-nitivas, as formas e categorias de percepção, os princípios de visão e de divisão: os agentes sociais constroem o mundo social através de estruturas cognitivas..."
É esta a dominação simbólica da qual nos fala Bourdieu, violência que se manifesta basicamente por avaliações dos agentes que compõem este espaço de possíveis que, através de um processo de inculcação exercido através de publicações cotidianas, vão garantindo um discurso reconhecido e legítimo. Difuso em muitas práticas, esse tipo de dominação forma sistemas de gestão da informação e do conhecimento (como as escolas e os jornais).

Nesta forma, as páginas desse jornal mostram indicadores de um futuro próximo complexo e as representações sociais são construídas pelos agentes que pretendem fazer acontecer aquilo que enunciam ${ }^{10}$.

$O$ fato de o trabalho assumir novas características é também bastante destacado e fornece a esta pesquisa evidência consistente da construção de novos conceitos.

"O trabalho se tornará redundante na emergente sociedade informatizada, mas será diferente...Graças à posse das ferramentas imateriais da informática, o trabalhador será assim como um profissional liberal diante de empregadores múltiplos e até mesmo de nenhum empregador...A informação e o seu conhecimento serão seu capital...Se a sociedade industrial proporcionou ao homem as melhores condições de vida da história, a sociedade informática será um espetacular salto para frente, não um retrocesso à barbárie ${ }^{11}$.

O advento da informática provoca mudanças sem precedentes no campo econômico. O trabalhador sem um contrato definido de trabalho, executando tarefas múltiplas ou mesmo trabalhando por conta própria, é o que o atual mercado de trabalho requer. Isso não deverá representar, segundo o jornal, nenhum retrocesso e sim um ganho. A idéia contida 
no texto inclui liberdade e melhor qualidade de vida.

Essa nova maneira de se trabalhar diz respeito à representação do trabalho autônomo. E este evidencia a importância da formação neste novo contexto de mudanças, acabando por focalizar o perfil profissional que melhor se adequará às necessidades do mercado de trabalho futuro. O poder de um periódico é proporcional ao reconhecimento que recebe do grupo, logo, pode-se dizer que vem daí a eficácia de seu discurso sobre o mundo social ${ }^{12}$.

A insistência na divulgação dessas idéias pretende a ruptura. $O$ conceito de trabalho mudou, e este é um dos avisos mais corriqueiros encontrados nas páginas de Zero Hora: o emprego como temos hoje não existirá mais. O jornal como uma instância de dominação e campo de produção simbólica, em que as ideologias são duplamente determinadas tanto por interesses de classe como por interesses de cada campo de produção, apresentase como um espaço de excelência para o registro dessas rupturas. Isso porque o poder simbólico é um poder quase mágico, que se equivale ao poder da força física ou econômica, tem o efeito de mobilização, só se exerce se for reconhecido e não imposto arbitrariamente. Assim, o que faz o poder das palavras é a crença na legitimidade delas e daquele que as pronuncia $^{13}$. O reconhecimento que esse periódico tem junto a seu público leitor vai rompendo com práticas legitimadas pelo tempo e estabelecendo outros novos conceitos.

$E$ é justamente no sentido de conscientizar a sociedade, ou seja, de desencadear um processo de inculcação que possa ser necessariamente incorporado aos habitus ${ }^{14}$ dos agentes que compõem esse espaço social, é que o periódico contribui para legitimar um discurso. As orientações diárias mostram a emergência de uma mudança profunda, capaz de romper com o hábito e assim colaborar sobremaneira para a ruptura pretendida.

No encaminhamento dessas idéias, ressalta a importância dos produtores do jornal. As páginas centrais do periódico são normalmente ocupadas por um agente, cujo capital simbólico exerce grande fascínio junto ao público leitor. Um desses agentes jornalísticos, autor do artigo selecionado a seguir, merece destaque neste estudo por deter um prestígio consagrado por um capital simbólico (experiências acumuladas anteriormente que lhe garantem um reconhecimento junto ao público), social e até mesmo juridicamente adquirido, conhecido e reconhecido ${ }^{15}$;

“'Emprego' não é uma 'coisa', um objeto tangível. É uma relação que se dá dentro do processo produtivo, isto é, de tudo o que produz algum 'bem' ou 'serviço', inclusive o governo (por imprestável que pareça. (...)As economias modernas estão sempre em processo de transformação. E o progresso tecnológico, aumentando a produtividade, pode levar à substituição de alguma mão-deobra, por novas máquinas, por exemplo .... Segurar a tecno-logia não é solução... A experiência tem demonstrado, porém, que um mercado de trabalho livre e flexível acaba sendo bem mais eficiente do que as políticas intervencionistas oficiais(...)A excessiva regulamentação do mercado de trabalho, somada aos custos sociais, gerou corporativismo, marginalização e desemprego... Mais da metade dos trabalhadores está na informalidade, e há um enorme incentivo a substituir mão-de-obra por máquinas e equipamen-tos ...porque os riscos são muito menores....

Muitos, por exemplo, querem mais empregos e menos capital estrangeiro ....Outros querem, por meio do protecionismo, preservar empregos em indústrias ineficientes, 
deixando de criar empregos eficientes na exportação. Os que mais protestam contra o desemprego são também os que mais defendem nossa obsoleta legislação trabalhista, intimidante para investidores. Pois, como dizia o presidente Reagan, difícil investir num país onde despedir um empregado é, às vezes, mais difícil que se divorciar de uma mulher"16.

Temos aqui um texto bem escrito, articulado e, conseqüentemente, capaz de prender a atenção do leitor. Porém, um texto muito denso que requer outras leituras se a proposta for esmiuçá-lo para uma análise mais detalhada. Contudo, a tônica do discurso é uma só. Comprometido em instaurar mudanças, esse agente social compõe o mercado de trabalho necessário ao próximo século. Critica o Estado e as regulamentações excessivas que sobrecarregam os custos sociais do Brasil e arremata de modo irônico imputando ao expresidente dos EUA o comentário de que não é um bom negócio investir num país de estruturas tão ultrapassadas. Articulado, elegante no trato com as palavras e consistente na legitimação de um discurso, esse agente tem espaço garantido nos editoriais da ZH dominical.

A sempre presente "idéia de ruptura" e a grande dificuldade desta tomada de posição, tendo em vista todas as garantias trabalhistas às quais a sociedade está habituada, são o destaque do espaço reservado a campos no periódico. A bandeira da renovação das leis trabalhistas é levantada por ele na maioria das discussões que implementou ao longo desses dois anos em que estive a pesquisar o jornal. Esse agente encampou conscientemente a preconização dessas idéias. Sabedor das dificuldades que envolviam tal ruptura, sua atuação incluía extrema pressão e sem a qual julgo não ser possível reverter normas duráveis de convivência social.

Enfim, o mercado de trabalho, ao assumir novas características, possibilita a construção de várias representações sociais que encontram neste periódico um campo fértil para a proliferação de idéias relativas à necessidade de mudança.

\section{Formação contínua: uma questão decisiva}

Considera-se aqui o material levantado junto ao periódico no que diz respeito à formação contínua, lembrando que esta se define como um processo de valorização social que envolve diversos tipos de conhecimentos, cuja aquisição se dá através de um processo contínuo e múltiplo. Esse conceito foi considerado por este estudo, principalmente porque a formação contínua também inclui uma disposição da sociedade em oferecer oportunidades de formação a qualquer momento, conforme as necessidades sentidas.

As práticas do Estado e da sociedade civil: medidas que facilitam $o$ acesso ao emprego

A demanda por formação contínua fica mais clara na medida em que o Estado passa a desencadear avaliações, medidas institucionais, estudos e discussões que vinculam os espaços de formação às necessidades básicas da comunidade.

Para compreender a lógica mais profunda do mundo social faz-se necessário um mergulho na particularidade de uma realidade historicamente situada e datada, para, então, construí-la como "caso particular do possível". Isso inclui analisar as relações, considerar as posições sociais, as disposições (habitus ${ }^{17}$ ) e as tomadas de posições (escolhas) que os agentes fazem nos domínios mais diferentes da prática, seja na cozinha, nos esportes ou no microcosmo social que é o jornal.

Esta análise destaca que a preocupação da sociedade em geral com 
o problema da formação parece acentuarse a partir de 1996. E no campo do poder/ político, essa preocupação foi capaz de desencadear medidas significativas cujo primeiro passo foi pautado por diversas avaliações do ensino:

"A qualidade dos cursos de pósgraduação no Brasil está caindo, constatou uma avaliação feita pelo Ministério da Educação (MEC)... Foram analisados vários aspectos, entre eles a qualificação e o regime de trabalho do corpo docente, a produção dos professores e alunos, as disciplinas, o número de dissertações e teses concluídas e o número médio de realização dos trabalhos"18.

Ao apreciar essas considerações, é importante ter-se a compreensão de que "O Estado tem a capacidade de regular o funcionamento dos diferentes campos, seja por meio de intervenções financeiras (...), seja através de intervenções jurídicas..."19, e, por que não dizer, através de uma intervenção precedida de avaliações que permitisse a implementação de medidas institucionais consideradas como necessárias ao campo cultural num dado momento de nossa história.

A partir de então, de maneira recorrente vai-se encontrar o periódico tecendo vários comentários capazes de sustentar quaisquer reforços a programas de apoio relacionados à formação.

Ao se propor a dar respostas mais eficazes a uma questão que se vem apresentando de forma crescente e desafiadora para os próximos anos, o governo destaca a necessidade do treinamento não só para o emprego, mas também para o reemprego:

"Se a educação especializada de nível médio é essencial para assegurar condições de profissionalização a estudantes que não pretendem cursar a universidade, não menos importante é capacitar recursos humanos que, alijados da educação formal, buscam colocação ou recolocação no mercado de trabalho...Por outro lado é preciso considerar que os operários que perderam vagas em razão da sofisticação tecnológica das empresas - hoje um processo irreversível - só encontrarão novas oportunidades de aproveitamento se souberem se reciclar..."20

O chamamento à reciclagem, à continuidade dos estudos pela vida afora, é a tônica do discurso ressaltado por $\mathrm{ZH}$. Considera-se que, para compreender as mudanças que ora são implementadas nesse campo cultural, é preciso considerar os interesses específicos que aí são determinados. IEntretanto, neste início de século $X X I$, fica difícil imaginar trabalhadores quebrando computadores conforme registros históricos sobre as máquinas a vapor no século passado. Por isso, é provável que o processo econômico frente às suas crises de adaptação conte com ações sociais associadas na busca de soluções. Em meio a essas ações encontramos o jornal, de modo recorrente, convocando a sociedade como um todo a participar do processo de formação requerido pelo atual momento em que vivemos;

"A educação não deve ser responsabilidade exclusiva do Estado, afirmou o ministro Paulo Renato de Souza, ao defender o envolvimento da sociedade na melhoria da qualidade do ensino no país. O programa Acorda, Brasil - lançado pelo MEC em 1995 - tenta estimular essas parcerias... As parcerias com o MEC incluem empresas como a Fiat e a Sony e bancos como o Itaú, o HSBC Bamerindus e a Caixa Econômica Federal"21.

Sob essa perspectiva, pode-se 
compreender que os campos são palcos de uma revolução ${ }^{22}$,e no campo cultural não é diferente. A luta se dá entre os detentores do poder e os pretendentes a ele. Nesse embate se faz a história do campo. E nessa luta por imposição de idéias, ZH se vale dos discursos dos produtores do jornal, cujo capital simbólico tem o poder de legitimar as publicações cotidianas, para mostrar a importância da responsabilidade social na formação.

Entre as práticas instauradas em parceria com a sociedade civil está o Programa Piá 2000, o mais festejado pelo jornal. Este é apontado pelo governo gaúcho como o mais importante e abrangente programa social da história recente do Estado. Com o aval da Unicef, o Piá 2000 começou com os objetivos de combater a mortalidade infantil, a desnutrição, a evasão escolar, o analfabetismo e tirar meninos e meninas das ruas, e por $\mathrm{ZH}$ ele é assim destacado:

"O Piá 2000 se preocupa...dando uma ajuda financeira de um salário mínimo para cada criança. Em contrapartida, a criança deve deixar as ruas e voltar a estudar imediatamente... O futuro se inicia dentro da sala de aula...Acima da adesão ao programa que hoje tornou-o referência dentro da Unicef, está a conscientização do povo gaúcho e o compromisso governamental em ampliar ainda mais o atendimento aos gaúchos carentes... O esforço vale a pena..."23.

Aqui se ganha fôlego para compreender que todas as estratégias simbólicas utilizadas para a nomeação oficial tornam-se consenso coletivo porque são operadas por um mandatário do Estado. Nesse caso, pela voz dos componentes do atual governo, o programa acima mencionado é anunciado como referência nacional. Isso passa a ser uma verdade por tratar-se de um ponto de vista autorizado. Outras ações concomitantes e associadas podem ser observadas, na medida em que diferentes setores privados organizam-se como espaço de formação:

"Lição número um: a riqueza se cria. Lição número dois: se uma pessoa não tem objetivos claros, não vai a parte alguma. Lição número três: na vida, é necessário assumir riscos que devem ser calculados e ponderados. Esses são apenas alguns dos ensinamentos que a Associação Junior Achievement .... ajuda a formar hoje os empreendedores de amanhã... uma fundação educativa, sem fins lucrativos. Objetivo: levar aos jovens a idéia de que suas ambições podem tornar-se realidade na medida em que assumam o papel de arquitetos de seus próprios destinos. A idéia difundida em cerca de cem países chegou ao Rio Grande do Sul há três anos por intermédio de empresários gaúchos.... Queremos dar aos nossos jovens uma experiência que não tivemos: viven-ciar o mundo real dos negócios... Falar de competitividade não é apenas trazer indústria e infraestrutura, é cada vez mais captar o humano, preparar pessoas para atuar no mercado $24 "$ ".

Esse artigo traz a idéia de determinação, de ambição, de necessidade de se preparar para o mercado competitivo do mundo globalizado. A necessidade de se preparar o perfil empreendedor encontra-se de modo recorrente estampado nas páginas do periódico. A fórmula utilizada pela Júnior Achievement é a tão evocada parceria. No Rio Grande do Sul, esta associação conta ainda com o apoio de entidades representativas como a Federação das Indústrias do Estado do RS (Fiergs), a Federação das Associações Comerciais (Federasul) e o Serviço de Apoio às Micro e Pequenas Empresas (Sebrae/RS).

Aqui vale analisar como se vai constituindo o campo do poder, um 
espaço de relações de força entre os diferentes tipos de capital, cujas lutas vão se intensificando sempre que determinado interesse é posto em questão ${ }^{25}$.

No esforço de compreensão desse campo, pode-se dizer que o que está em jogo são os diferentes tipos de capital que os empresários detêm, pois é o que vai determinar a imposição ou não de suas idéias. As forças envolvidas nessas lutas dependem da "taxa de câmbio" entre esses diferentes tipos de capital. Ou seja, o poder de impor um discurso reconhecido pelo capital simbólico que detém.

Ao longo da exposição dessas idéias constata-se que a formação contínua dentro dos limites do treinamento vem superando a formação acadêmica e institucionalizada. Nessa medida, observa-se, através do texto de Zero Hora, extensa divulgação de estratégias voltadas à capacitação profissional imediata através das práticas do Estado e da sociedade civil, que demonstram claramente o compromisso do jornal em informar e orientar o leitor sobre o perfil profissional demandado nesse início de século.

Orientações pedagógicas:

a informação que forma

Para analisar o referido jornal como orientador e formador de opinião, é necessário considerar que as relações de comunicação por excelência são também relações de poder simbólico nas quais se atualizam as relações de força entre os locutores ou seus respectivos grupos ${ }^{26}$.

Observa-se que um modo de expressão (a língua e sua utilização) como produto da dominação política é reproduzido ininterruptamente por instituições capazes de impor um reconhecimento universal junto ao público leitor. No processo de constituição de um mercado lingüístico unificado, o periódico propicia o espaço ideal para o embate de idéias, exposição de conflitos e da luta por visões de mundo.

Nesta medida, percebe-se o jornal Zero Hora interagindo de maneira muito mais associativa do que conflitiva com o campo do poder. As orientações pedagógicas ali registradas tinham por objetivo instaurar práticas que legitimavam um perfil profissional adequado ao próximo século.

Esse poder de imposição e de inculcação de uma determinada idéia como verdade universal é alcançado através dos mecanismos de dominação simbólica que se constituíram num pensamento pedagógico. De modo recorrente, recomendações como esta selecionada abaixo dão o tom do discurso:

"Quem quiser se formar e conseguir empregos... vai precisar ter suas habilidades tecnológicas bem desenvolvidas... Em termos de ciência e tecnolo-gia ou tudo que diga respeito a habilidades, o que se aprende hoje não serve para amanhã... A maioria das profissões do próximo século ainda não foram inventadas... É preciso ser criativo, tomar decisões com informações incompletas, ser independente, ter iniciativa"27.

Ponderações que falam efetivamente de mudanças vertiginosas, de uma realidade diante da qual é preciso inovar a cada momento. É o chamamento à prontidão, considerando que a maioria das profissões não foi ainda sequer inventada. Um mundo totalmente novo é anunciado, o que pressupõe uma formação muito flexível, construída num vôo cego, pois não se sabe ao certo que tipo de profissionais a sociedade "precisa" formar.

Assinala-se aqui a função do habitus: a estruturação e incorporação de estruturas imanentes de um mundo ou de um campo capaz de assegurar a percepção e reprodução de um modus operandi (um modo de agir) neste mundo ${ }^{28}$. Nesta perspectiva, puderam ser analisadas as orientações pedagógicas com a observação 
de que o conteúdo veiculado nas páginas do jornal só encontra ressonância mediante a percepção estruturada dos agentes que compõem o espaço social. Os temas debatidos por ZH visavam a certos "alvos", e estes eram perseguidos através de uma ação pedagógica capaz de guiar e conduzir os diversos agentes/leitores para a aquisição de habilidades necessárias a um certo profissional.

Nesta perspectiva é que se procura destacar o desafio de refletir sobre a dominação simbólica exercida pelo jornal. O mecanismo utilizado pela imposição de idéias pretende a não discussão da formação que está sendo proposta. É como se esta fosse uma opção natural. Porém, "nada é natural na história" (Pellanda 2000). Esta é, antes de tudo, um processo de construção humana, o que nos responsabiliza frente a todo $e$ qualquer acontecimento. $\mathrm{O}$ mecanismo da dominação simbólica induz as pessoas a não reagir e a aceitar com "naturalidade" o perfil profissional desenhado por $\mathrm{ZH}$. $\mathrm{Na}$ medida em que a instauração de um paradigma atinge as práticas sociais como um todo, julga-se ser esta questão merecedora de questionamentos mais contundentes.

$O$ fato de a formação passar a ser a nova ferramenta utilizada pelo mundo no advento da globalização da economia faz parecer natural que o mercado passe a requerer profissionais altamente qualificados.

Entretanto, os problemas são totalmente novos e desafiadores. Convém também refletir sobre 0 imenso fluxo de informações que nos chegam a todo instante, fazendo com que os conhecimentos, muitas vezes transmitidos como definitivos, sejam rapidamente superados. E assim, aquela demanda que parecia natural dá lugar a questionamentos ainda mais perturbadores para aqueles que se interessam pela formação de um modo geral. As complexas demandas sociais exigem uma formação também complexa e dinâmica. Dessa forma, não podemos mais nos limitar a formar prioritariamente o profissional "acabado", pronto para - mercado, como se esta atualização provisória garantisse o privilégio vitalício do exercício profissional. O desafio da formação seria então o de possibilitar um aprendizado que permitisse apreender e assimilar o mundo em que vivemos em condições de transformá-lo, e não de reproduzi-lo.

O fato é que existem certas condições sociais para que a magia das palavras possa operar. É quando funciona um conjunto de mecanismos capazes de assegurar a reprodução da relação de reconhecimento na qual está fundada a autoridade de um periódico. E pode-se dizer que as condições sociais deste momento de nossa história asseguram a produção de emissores e receptores adequados, ajustados uns aos outros. Está em jogo o chamamento ao novo e a capacidade de se articular frente a tanta mudança. Assim, tem eficácia a imposição simbólica da linguagem periódica que enquanto informa também forma os agentes sociais que compõem o espaço social.

Considerações finais:

vasculhando o jornal

Ao vasculhar $\mathrm{ZH}$, deparei-me com um jornal de grande alcance, já estruturado segundo as exigências de um mundo capitalista globalizado. Em sua vitrine diária, uma gama variada de autores capazes de instaurar com competência um discurso propício à implementação de novas práticas relativas à formação de um novo profissional.

Ao longo deste estudo, considerei a formação como um fato histórico cuja construção se dá no cotidiano de forma extremamente dinâmica pelo texto do jornal. E pelas páginas da ZH vi surgir uma proposta de formação que, muitas vezes, prioriza o treinamento com vistas à inserção profissional imediata. Observei ações do Estado e da sociedade civil, comprometidos 
também em esculpir um profissional em moldes descartáveis se considerarmos que o treinamento produz um instrumento incapaz na mão de empresários, que dele se utilizam e depois o descartam quando não serve mais.

O periódico constrói o seu discurso respaldado pela idéia de que para um mundo que muda tão depressa nos restaria a adaptação da mão de obra despreparada. Num curto espaço de tempo, provavelmente, atenderíamos as demandas de um mercado emergente e ocuparíamos os espaços oferecidos aos cargos mais especializados, mas a longo prazo comprometeríamos gerações. Entretanto, procurando não cair num ensaio denuncista, tentarei tratar os fatos em sua positividade, propondo superar a simples factualidade jornalística para apreender a essência desse processo social.

Ao final deste sistema de idéias, percebi o periódico como agente formador de opinião produzindo, num movimento constante e infinito, conceitos e práticas relativos à formação. Montado o quebracabeça, pude verificar a composição do perfil profissional necessário ao século XXI. De forma contínua e amparado por agentes sociais cujo capital simbólico tem reconhecimento junto ao público leitor, esse jornal exerce sua função de formador, instaurando práticas que, perpetuadas, possibilitarão o alinhamento da sociedade como um todo às demandas atuais.

No conjunto destas reflexões finais, é importante relembrar que um pensamento inquieto desconfia da realidade aparente e exige mais aproximações e, portanto, mais ocasiões para investigar. As demandas sociais deste início de século mostram a necessidade de reformulações dos espaços voltados à formação. Não se trata apenas de uma exigência das novas formas de trabalho, mas de uma necessidade pessoal de cada profissional na compreensão crítica de um mundo cada vez mais complexo e globalizado. $O$ homem inserido na trama das relações sociais é pressionado por novas exigências do mundo do trabalho, porém o que está em pauta é uma nova relação com o trabalho. $O$ treinamento foi uma dimensão interessante quando nos ensinava a seguir instruções. Hoje a relação homem $x$ trabalho tornou-se muito mais complexa. A demanda atual é por um agente social participativo e atuante na tomada de iniciativa num contexto de mudança, e só uma formação globalizante poderá propiciar a tão proclamada "tomada de decisões" tantas vezes mencionada nas páginas desse jornal.

Considero que esta investigação foi uma tentativa de aquisição do conhecimento pelo esforço científico. Nesta perspectiva, destaco que o periódico Zero Hora exerce sua função de formador, instaurando saberes que, repetidos sistematicamente possibilitam a construção de novas concepções e práticas relativas à formação. Finalmente, julgo que a importância desta análise está em articular o processo de formação desencadeado pelo periódico Zero Hora à dinâmica dos vários campos que compõem o espaço social. Isto, aprendi com Pierre Bourdieu

\section{Notas}

1 Mestre e doutoranda junto ao PPGSS / PUCRS, bolsista $C N P Q$, sob a orientação da profa. dra. Jussara Mendes.

2 Esta pesquisa foi realizada sob a orientação da prof̣̂: dra. Julieta Beatriz Ramos Desaulniers e financiada pela Coordenação de Aperfeiçoamento de Pessoal de Nível Superior (Capes).

30 jornal ZH é o principal veículo da mídia impressa da Rede Brasil Sul (RBS). É um jornal em formato de tablóide com circulação diária, sendo domingo o seu maior dia de circulação. Segundo pesquisa realizada junto a leitores diários de jornais no RS, num total de 1.014 .600 (48\% da população): 709.000 (34\%) são leitores de ZH e 448.800 (21\%), são leitores do Correio do Povo (Fonte: Ibope/dez/ 97 a fev/98). 
4 Catedrático de sociologia do Collége de France, Pierre Bourdieu morreu em Paris no dia 23/1/01 aos 71 anos ,vítima de câncer. 0 sociólogo era considerado como um dos intelectuais mais influentes de sua época.

5 DRUCKER, Peter apud William Bridges. "Mudanças nas relações de trabalho" in: ZH/Caderno de Economia 28/4/ 96, p. 2.

\section{DRUCKER, 1996;2.}

7 CAMPOS, 1997; 24.

8 BOURDIEU, 1989; 55

9 BOURDIEU, 1996; 115.

10 BOURDIEU,1989;145

11 FREITAS, Décio. "Editoriais" in: ZH, 1/9/96 p. 17.

12 BOURDIEU, 1989; 145.

13 BOURDIEU, 1989; 14.

14 Esse termo diz respeito aos hábitos precocemente transmitidos pela educação, principalmente a familiar, os quais constituem condutas profundamente arraigadas através da repetição, capaz de engendrar ações previsíveis. Habitus pode ser também compreendido como a capacidade, adquirida socialmente pelo indivíduo, de estabelecer suas relações sem antes refletir, pois os esquemas de habitus devem sua eficácia ao fato de funcionar a despeito da consciência e do discurso, portanto, fora do exame e controle voluntário.

15 Roberto Campos foi deputado federal, muito conhecido do público por ter atravessado décadas ocupando posições de destaque junto ao poder central. Não se discute aqui a postura ideológica deste agente produtor do jornal, falecido no ano passado. Mas há de se considerar sua inteligência, lucidez e poder de argumentação, na publicação de vários textos nos quais trabalha pela imposição de sua visão de mundo.

16 CAMPOS, Roberto. "A pajelança não cria empregos". In: ZH Opinião, 3/5/98, p.18.

17 Relembrando que esse conceito é discutido por Pierre

\section{Referências}

AGUIAR, Vera Teixeira de. "Pierre Bourdieu e as Regras do Campo Literário" in: Revista Véritas, v. 41, n.162, jun/96.

ANTUNES, Ricardo L. Adeus ao Trabalho? Ensaios sobre as Metamorfoses e a Centralidade do Mundo do Trabalho. São Paulo: Cortez, 1995.

BACHELARD, Gaston. O Novo Espírito Científico. São Paulo: Edições 70, 1984.

BOURDIEU, P. A Economia das Trocas Lingüísticas. São Paulo: Editora da Universidade de São Paulo, 1996.

—. Coisas Ditas. São Paulo: Brasiliense, 1987. La distintion. Paris: De Minuit, 1979.

Razões práticas: sobre a teoria da ação. São Paulo: Papirus, 1996.

0 Poder simbólico. Rio de Janeiro: Bertrand do Brasil, 1989.

et al. El Ofício de Sociólogo: Presupuestos Epistemológicos. Espana: SIGLO Veintiuno Editores, 1983.

BOURDIEU, P. Esquisse d'une théorie de la pratique apud ORTIZ, Renato (org). Pierre Bourdieu, Coleção Grandes Cientistas Sociais (39). São Paulo: Ática, 1983.

DESAULNIERS, Julieta B. R. "Formação, Qualificação ou Competência..." In Veritas - Revista Trimestral de Filosofia e Ciências Humanas da PUCRS.,V, n. 149, mar/1993.

Julieta B. R. Formação, Competência e Cidadania. Educação \& Sociedade: revista quadrimestral de Ciência da Educação/Centro de Estudos Educação e Sociedade(Cedes), n. 59- 1997, p. 51.

Julieta B. R. Formação via impresso. In Educação em Revista - A imprensa periódica e a história da educação. São Paulo: Escrituras, 1997, vários autores.

DELUIZ, Neise. Formação do Trabalhador em Contexto de Mudança Tecnológica. In Boletim Técnico do SENAC, jan/abr. 1994. 
DINES, Alberto. $O$ papel do jornal. São Paulo: Summus, 1986. GARCIA, Walter. Educação: visão teórica e prática pedagógica. São Paulo: McGraw-Hill do Brasil, 1977.

GASPARD, Pierre e Penélope. "Imprensa pedagógica e formação contínua dos professores primários", in Educação em Revista: A imprensa periódica e a história da educação. São Paulo: Escrituras, 1997, vários autores.

FOULQUIÉ, Paul apud DESAULNIERS, Julieta B. R. "Emergência e construção do campo de pesquisa sobre a inserção profissional", in Formação \& Trabalho \& Competência,, DESAULNIERS, J. B. R (org), Porto Alegre: EDIPUCRS, 1998.

HAGUETE, Tereza M. Frota. "Universidade: Nos Bastidores da Produção do Conhecimento", in ANPED, 23-30, out/94 (XVIII Reunião Anual, Caxambu, MG)

HOBSBAWM, Eric. Era dos extremos: 0 breve século XX : 1914-1991. São Paulo: Companhia das Letras, 1995.

LIEDKE, Élida R. "Novas formas de relações do trabalho", in Seminário Internacional: Trabalho e Reordenamento Social, Porto Alegre, maio/96.

LOPE Y ARTILES. "Las relaciones entre formación y empleo: que formación, para que empleo", in Formação \& Trabalho \& Competência,, DESAULNIERS, J. B. R (org), Porto Alegre: EDIPUCRS, 1998.

LOPES, M. Immacolata V. Pesquisa em comunicação: formulação de um modelo pedagógico. São Paulo: Loyola, 1994.

LUDKE, Menga \& ANDRÉ, Marli E. D. A Pesquisa em Educação: Abordagens Qualitativas. São Paulo: EPU, 1986.

MORIN, Edgar \& KERN, Anne Brigitte. Terra - Pátria. $2^{0}$ ed. Porto Alegre: Sulina, 1995.

MOTTA, Paulo Roberto. Transformação Organizacional: a teoria e a prática de inovar. Rio de Janeiro: Qualitymark, 1998.

NÓVOA, Antônio. "A imprensa de educação e ensino: concepção e organização do repertório português", in: Educação em Revista: A imprensa periódica e a história da educação. São Paulo: Escrituras, 1997, vários autores.
PELLANDA, Nize Maria Campos. "Novos Paradigmas do Conhecimento em Início de Milênio", in Folha de São Paulo, 06/04/2000.

RÉGNIER, Erna Martha. "Desafios da Educação para 0 Terceiro Milênio: breves considerações", in Boletim Técnico do Senac, jan/abr, 1993.

RIFKIN, Jeremy. 0 Fim dos Empregos: 0 Declínio Inevitável dos Níveis dos Empregos e a Redução da Força Global de Trabalho. São Paulo: Makron Books, 1996.

TADDEI, E. H. "Empregabilidade e formação profissional: a nova" face da política social na Europa in: Escola Cidadã no Contexto da Globalização, vários autores, Petrópólis: Vozes, 1998, p. 340.

TANGUY, Lucie. "Formação uma atividade em vias de definição?" In: Revista Véritas, Porto Alegre: EDIPUCRS, Vol.

42, no. 2, junho/95, p.385-410.

TROTTIER, Claude. "Emergência e construção do campo de pesquisa sobre a inserção profissional" in Formação \& Trabalho \& Competência,, DESAULNIERS, J. B. R (org), Porto Alegre: EDIPUCRS, 1998. 